\title{
COMPARATIVE ANALYSIS OF THE CLEANING ABILITY OF SINGLE FILE VERSUS MULTIPLE FILE SYSTEM (AN IN VITRO STUDY)
}

\author{
Shady Nabil Ibrahim*, Amr Ahmed Bayoumi** and Ehab Sayed Hassanein ${ }^{* * *}$
}

\begin{abstract}
Aim: The purpose of this study was to assess smear layer removal following canal preparation with single file (One Shape file) and multiple file system (Protaper Universal files).

Methodology: Sixteen freshly extracted mandibular molars were tested and divided into two experimental groups $(n=8)$ : group 1 , cleaning and shaping was done using One Shape file (8 canals); and group 2, cleaning and shaping was done using a kit of Protaper Universal Files till file F2 (8 canals). Two grooves were prepared on the lingual and buccal surfaces of the instrumented roots by disc to facilitate vertical splitting with a chisel after canal instrumentation. The presence of smear layer was evaluated under SEM in the apical, middle and coronal thirds of the canals. Blind evaluation was done by two trained evaluators and scores were complied separately. Data were then collected, tabulated and statistically analyzed.
\end{abstract}

Results: Smear layer scores showed no statistically significant difference either in comparison between the two systems or between different root levels in each group.

Conclusions: Under the condition of the current study, both rotary systems failed to remove smear layer at different root canal levels using saline only as an irrigant.

\section{INTRODUCTION}

Biomechanical preparation, disinfection and obturation all together constitute equally important phases of the endodontic treatment. A successful outcome of root canal treatment depends on several factors such as, adequate cleaning of the root canal by removing infected and necrotic pulp remnants, elimination of microorganisms, complete removal of debris and smear layer to produce a perfect seal between the filling material and the root dentin, which is important on the outcome of the root canal treatment $^{(1,2)}$.

Smear layer may be one of the common causes of root canal treatment failure. Debris contains vital and/or necrotic pulp tissue and dentinal chips that loosely attach to the root canal walls, it is usually

\footnotetext{
* B.D.S (Misr International University)

** Lecturer of Endodontics (Misr International University)

*** Professor of Endodontics, Chairman of Endodontic department (Ain-Shams University)
} 
infected ${ }^{(3,4)}$. The smear layer consists of dentin particles, remnants of vital or necrotic pulp tissues, bacterial components, and retained irrigants. The smear layer is reported to prevent the penetration of irrigating solutions, medications and filling materials into dentinal tubules, thus affecting the outcome of the root canal treatment ${ }^{(5,6,7,8)}$.

The basic design of root canal instruments has changed very little over the years, apart from the minor modifications such as new materials, improved cutting edges and greater flexibility. One of the many innovations in root canal instruments is the use of nickel titanium for file manufacture, which have two to three times more elastic flexibility than stainless steel files and appear to be more fracture resistant compound to stainless steel files ${ }^{(9,10)}$.

Only a few studies have been published on the cleaning ability of rotary Ni-Ti files (11,12,13,14,15,16,17). From these rotary files are ProTaper Universal files (multiple file system) and One Shape file (single file system) which may help in removal of smear layer during endodontic treatment and thus increasing the quality of root canal treatment.

The purpose of this study was to assess smear layer removal following canal preparation with One Shape single file and Protaper Universal files.

\section{METHODOLOGY}

\section{Tooth selection}

Sixteen mandibular molars were selected according to simple root curvatures of distal canal without open apex, resorption or calcifications. The teeth were cleaned in order to remove any tissue debris, autoclaved and stored in saline until the moment of use. Before canal instrumentation, de-coronation of the teeth was performed by using a high-speed carbide bur and water spray to standardize to average length of $16 \mathrm{~mm}$.

\section{Root canal preparation}

Coronal access was completed using diamond burs, and the apical patency was done using root canal instrument of size 10 (Dentsply- Maillefer, Ballaigues, Switzerland). Only teeth with intact root apices, and whose root canal width near the apex was approximately compatible with a size 15 instrument, were included.

Teeth were randomly divided into two main groups to test the smear layer removal:

Group1: cleaning and shaping was done using One Shape file (8 canals).

Group2: cleaning and shaping was done using Protaper Universal rotary files (8 canals).

A glide path was made by using a size $10 \mathrm{~K}$ file and a size $15 \mathrm{~K}$ file to reach the apex of the canal before working with the rotary files to avoid the breakage of the rotary files while working inside the canals. The working length was determined by placing a size $15 \mathrm{~K}$ file into the canal until it was observed at the apical foramen, then the file withdrawn and one millimeter was subtracted from the measured length and recorded as the working length.

After reaching the full working length with size $15 \mathrm{~K}$ file, all the canals in Group 1 were instrumented by size 25 One Shape file with taper of 0.06 in a rotating motion was used in a 16:1 gear reduction hand-piece powered by a torquecontrolled electric motor at a consistent rotation of $400 \mathrm{rpm}$, the torque was adjusted to $2.5 \mathrm{Ncm}$ according to manufacturer's instructions. While in Group 2 the canals were instrumented by the set of Protaper files (SX-S1-S2-F1-F2) in a rotating motion was used in a 16:1 gear reduction handpiece powered by a torque-controlled electric motor at a consistent rotation of $350 \mathrm{rpm}$, the torque was adjusted to $2 \mathrm{Ncm}$ according to manufacturer's instructions. Apical patency was preserved using K-file size 10 following each file. Irrigation was 
carried out by using a 27 gauge needle with Saline solution between each file.

\section{SEM Examination}

Two grooves were prepared on the lingual and buccal surfaces of the instrumented roots by disc to facilitate vertical splitting with a chisel after canal instrumentation.

The sections are observed under SEM in the coronal, middle, and apical thirds for evaluation of the smear layer. Evaluations will be assessed by scoring system (2):

Score 1: No smear layer, dentinal tubules open.

Score 2: Small amount of smear layer, some dentinal tubules open.

Score 3: Homogenous smear layer covering the root canal wall, only few dentinal tubules open.

Score 4: Complete root canal wall covered by a homogenous smear layer, no open dentinal tubules.

Score 5: Heavy, non-homogenous smear layer covering the complete root canal wall.

\section{Statistical Analysis}

Smear layer scores (non-parametric data) were presented as median and range values. Mann-
Whitney $U$ test was used to compare between the two systems. Friedman's test was used to compare between different root levels within each system. The significance level was set at $\mathrm{P} \leq 0.05$. Statistical analysis was performed with IBM ${ }$ SPSS $®$ Statistics Version 20 for Windows.

\section{RESULTS}

\section{Comparison between the two systems}

Statistical analysis showed that either at the apical, middle as well as coronal root levels; there was no statistically significant difference between median smear layer scores of the two systems.

Similarly for the total smear layer scores regardless of root level; there was no statistically significant difference between median smear layer scores of the two systems.

\section{Comparison between root levels within each group}

Either with ProTaper Universal or One Shape systems; there was no statistically significant difference between median smear layer scores at different root levels.

TABLE (1): Descriptive statistics and results of Mann-Whitney U test for comparison between smear layer scores in the two groups

\begin{tabular}{lcccccc}
\hline \multirow{2}{*}{ Root level } & \multicolumn{2}{c}{ ProTaper Universal } & \multicolumn{2}{c}{ One Shape } & \multirow{2}{*}{ P-value } & Effect size $(r)$ \\
\cline { 2 - 5 } & Median & Range & Median & Range & & \\
\hline Apical & 4 & $3-5$ & 3 & $3-5$ & 0.328 & 0.285 \\
Middle & 3 & $2-3$ & 4.5 & $2-5$ & 0.050 & 0.539 \\
Coronal & 3 & $2-5$ & 3 & $2-4$ & 0.195 & 0.355 \\
Total & 3.3 & $2.7-4$ & 3.3 & $2.7-4.3$ & 0.957 & 0.014 \\
\hline
\end{tabular}

*: Significant at $P \leq 0.05$ 
TABLE (2): Descriptive statistics and results of Friedman's test for comparison between smear layer scores at different root levels within each group

\begin{tabular}{lcccc}
\hline & \multicolumn{2}{c}{ ProTaper Universal } & \multicolumn{2}{c}{ One Shape } \\
\cline { 2 - 5 } Root level & Median & Range & Median & Range \\
\hline Apical & 4 & $3-5$ & 3 & $3-5$ \\
Middle & 3 & $2-3$ & 4.5 & $2-5$ \\
Coronal & 3 & $2-5$ & 3 & $2-4$ \\
\hline$P$-value & \multicolumn{2}{c}{0.054} & \multicolumn{2}{c}{0.223} \\
\hline Effect size $(w)$ & \multicolumn{2}{c}{0.243} & \multicolumn{2}{c}{0.125} \\
\hline
\end{tabular}

*: Significant at $P \leq 0.05$

\section{DISCUSSION}

The cleaning and shaping of the root canal is a key procedure in root canal treatment. The aim of cleaning is the removal of tissue remnants and bacterial biofilms in order to allow close adaptation of the root filling to the canal walls. If root canals could be thoroughly cleaned using irrigation alone and effectively obturated, there would be no need for mechanical instrumentation. However, with the currently available technologies, this is not yet clinically possible. Recently, a new concept of mechanical instrumentation was introduced to allow effective cleaning while avoiding excessive removal of sound dentin, which potentially could lead to minimally invasive endodontic treatment ${ }^{(18)}$.

The smear layer in a cavity and in the root canal may not be directly comparable. Not only are the tools for dentin preparation different in coronal cavities, but in the root canal the dentinal tubule numbers show greater variation and there are likely to be more soft tissue remnants present. The first researchers to describe the smear layer on the surface of instrumented root canals were McComb \& Smith (1975). They suggested that the smear layer consisted not only of dentin as in the coronal smear layer, but also the remnants of odontoblastic processes, pulp tissue and bacteria. Lester \& Boyde (1977) described the smear layer as 'organic matter trapped within translocated inorganic dentin'. As it was not removed by sodium hypochlorite irrigation, they concluded that it was primarily composed of inorganic dentin ${ }^{(19)}$.

The purpose of this study was to compare smear layer removal following canal preparation with single file system (One Shape single file) and multiple file system (Protaper Universal files). Human extracted teeth were used in our study to provide conditions similar to clinical situations as well as providing electron microscopic examination for canal cleanliness following canal preparation ${ }^{(20)}$.

The files used in this current study were Protaper Universal files and One Shape files. We used these files as to compare the ability of single file system (One Shape) and multiple files system (Protaper Universal files) to remove smear layer. To achieve equitable results the Protaper Universal system was used to file F2 as it has a tip size of 25 to be as the tip size of One Shape file. A multiple researches have been through the concept of single file system for the aim of decreasing number of files used thus reducing time and effort ${ }^{(21)}$.

Saline was used in this current study in order to show the effect of files only, not the chemical agent in removal of smear layer and debris removal. As other irrigation systems will participate in the removal of smear layer and debris ${ }^{(22)}$.

The scoring system used in this current study was Hulsmann et al. scoring system as it is one of the mostly used systems in debris removal and smear layer removal studies. The root of each tooth was divided in three sections; apical, middle and coronal, in order to show the effect of files in smear layer and debris removal in each part of the canal.

Histological sections, viewed at high magnification, were apparently the best method for evaluating the cleanliness of the canal wall. 
There are two methods for evaluating smear layer, Scanning electron microscope (SEM) and stereo microscope. SEM has a magnification with range of 1000X to $3000 \mathrm{X}$, while stereo microscope has a magnification with a range of $30 \mathrm{X}$ to $70 \mathrm{X}$. So using SEM will have a better evaluation of the smear layer and debris removal inside the canal and can reveal the nature of the instrumented surface of the canal and show whether a layer of dentin was removed as well as disclose any pulp tissue or bacterial biofilm that remained attached to the canal wall after the cleaning and shaping procedure ${ }^{(23,24,25,26,27)}$. So when it is needed to evaluate smear layer and debris removal in the root dentin it is better to use SEM not stereo microscope.

Results showed that there was no statistically significant difference between single file system (One Shape file) and multiple file system (Protaper Universal files) in removal of smear layer, both systems failed to remove the smear layer in the coronal, middle, and apical thirds with no significant difference between the three levels. This may be attributed due to the use of saline only as an irrigating solution in the present study which lacks the tissue dissolving action which is unique in sodium hypochlorite as it is considered our gold standard irrigant. Removal of smear layer during or after root canal instrumentation requires the use of irrigants that can dissolve both organic and inorganic components. This reflects the importance and the power of both irrigating solutions and chelating agents such as 17\% EDTA, citric acid, and MTAD in removal of smear layer.

Our results also showed no statistically significant between single file system (One Shape file) and multiple file system (Protaper Universal files) this may be due to increased number of strokes done with One Shape file for reaching the working length and shaping the canals leading to excessive amount of shredded dentin attached to the canal walls occluding the dentinal tubules.
Our findings were in agreement Azar et al (28) who reported that there was no significant difference regarding the median debris and smear layer scores of the two systems (Protaper and Mtwo files), while regarding the root level median scores they found a better cleaning at the middle and coronal thirds than in the apical third. The difference of findings between the current study and our study may be due to the usage of different files such as Mtwo files and using them in primary teeth.

\section{CONCLUSION}

Under the condition of the current study, both single file system (One Shape file) and multiple file system (Protaper Universal files) failed to remove smear layer at different root canal levels (coronal, middle and apical thirds) using saline only as an irrigant.

\section{REFERENCES}

1. Bolanos OR, Sinai IH, Gonsky MR, Srinivasan RA. Comparison of engine and air driven instrumentation methods with hand instrumentation. J Endod 1988;14: 392-6.

2. Hulsmann M, Rummelin C, Schafers F. Root canal cleanliness after preparation with different endodontic handpieces and hand instruments: a comparative SEM investigation. J Endod 1997;23:301-6.

3. Heard F, Walton RE. Scanning electron microscope study comparing four root canal preparation techniques in small curved canals. Int Endod J 1997;30,323-31.

4. Peters CA, Barbakow F. Effect of irrigation on debris and smear layer on canal walls prepared by two rotary techniques: a scanning electron microscopic study. J Endod 2000;25:6-10.

5. Orstavik D, Haapasalo M. Disinfection by endodontic irrigants and dressings of experimentally infected dentinal tubules. Endod Dent Traumatol 1990;6:142-9.

6. White RR, Goldman M, Lin PS. The influence of the smeared layer upon dentinal tubule penetration by endodontic filling materials (part II). J Endod 1987; 13:369-74. 
7. Kennedy WA, Walker WA, Gough RW. Smear layer removal effects on apical leakage. J Endod 1986;12:21-7.

8. Saunders WP, Saunders EM. The effect of smear layer upon coronal leakage of gutta-percha fillings and a glass ionomer sealer. Int Endod J 1992;25:245-9.

9. Ullmann CJ, Peters OA. Effect of cyclic fatigue on static fracture loads in ProTaper nickel-titanium rotary instruments. J Endod 2005;31:183-6.

10. Peters OA. Current challenges and concepts in the preparation of root canal systems: a review. J Endod 2004;30:559-67.

11. Hulsmann M, Schade M, Schafers F. A comparative study of root canal preparation with HERO 642 and Quantec SC rotary Ni-Ti instruments. Int Endod J 2001;34:538-46.

12. Hulsmann M, Gressman G, Schafers F. A comparative study of root canal preparation using FlexMaster and HERO 642 rotary Ni-Ti instruments. Int Endod J 2003;36:358-66.

13. Hulsmann M, Herbst U, Schafers F. A comparative study of root canal preparation using Lightspeed and Quantec SC rotary Ni-Ti instruments. Int Endod J 2003;36:748-56.

14. Schafer E, Lohmann D. Efficiency of rotary nickeltitanium FlexMaster instruments compared with stainless steel hand K-Flexofile. Part 2. Cleaning effectiveness and shaping ability in severely curved root canals of extracted teeth. Int Endod J 2002;35:514-21.

15. Versumer J, Hulsmann M, Schafers F. A comparative study of root canal preparation using Profile .04 and Lightspeed rotary Ni-Ti instruments. Int Endod J 2002;35:37-46.

16. Schafer E, Schlingemann R. Efficiency of rotary nickeltitanium K3 instruments compared with stainless steel hand K-Flexofile. Part 2. Cleaning effectiveness and shaping ability in severely curved root canals of extracted teeth. Int Endod J 2003;36:208-17.

17. Prati C, Foschi F, Nucci C, Monteburgnoli L, Marchionni $\mathrm{S}$, Appearance of the root canal walls after preparation with NiTi rotary instruments: a comparative SEM investigation. Clin Oral Investig 2004;8:102-10.

18. Kocak M, Kocak S, Saglam B, Turker A. Smear layer and debris removal following use of Wave One and One Shape single file system: SEM study. IJEDS 2014; 3(2): 77-83.
19. Violich DR, Chandler NP. The smear layer in endodontics - a review. Int Endod J 2010;43:2-15.

20. Williamson AE, Sandor AJ, Justman BCA. Comparison of three nickel titanium rotary systems, EndoSequence, Protaper Universal, and Profile GT, for canal cleaning ability. J Endod 2009;35:107-9.

21. Topcu KM, Karatas E, Ozsu D, Ersoy I. Efficiency of the Self Adjusting File, WaveOne, Reciproc, ProTaper and hand files in root canal debridement. Eur J Dent 2014;8:326-9.

22. Nischith KG, Sirkumar GPV, Razvi S, Chandra RV. Effect of smear layer on the apical seal of endodontically treated teeth: An ex-vivo study. J Contemp Dent Pract 2012; 13(1): 23-6.

23. Baumgartner JC, Mader CL. A scanning electron microscopic evaluation of four root canal irrigation regimens. $\mathrm{J}$ Endod 1987;13:147-57.

24. Mancini M, Cerroni L, Iorio L, Armellin E, Cont G, Cianconi L. Smear layer removal and canal cleanliness using different irrigation systems (EndoActivator, EndoVac, and passive ultrasonic irrigation): Field emission scanning electron microscopic evaluation in an in vitro study. J Endod 2013;39:1456-60.

25. Yang G, Wu H, Zheng Y, Zhang H, Li H, Zhou X. Scanning electron microscopic evaluation of debris and smear layer remaining following use of Protaper and Hero Shaper instruments in combination with NaOCL and EDTA irrigation. Oral Surg Oral Med Oral Pathol Oral Radiol Endod 2008;106:63-71.

26. Mandorah A. Effect of irrigation needle depth in smear layer removal: Scanning electron microscope study. Saudi Endod J 2013;3:112-9.

27. Gianluea P, Grande NM, Tocci L, Testarelli L, Gambarini G. Influence of different apical preparations on root canal cleanliness in human molars: A SEM study. J Oral Maxillofac Res 2014;5:e4.

28. Azar M, Safi L, Nikaein A. Comparison of the cleaning capacity of Mtwo and Pro Taper rotary systems and manual instruments in primary teeth. Dent Res J. 2012; 9(2): 146-51 